\title{
An Automatic High-Speed Rail CPIII Detection System With Multi-Sensor Fusion
}

\author{
Yi Han*, Yunde Zhao, Saiwei Zhang and Dongsheng Zhang
}

School of Automobile, Chang'an University, Xi'an, Shaanxi, 710064, China

\begin{abstract}
In order to measure the CPIII control network of high-speed rail quickly and accurately, we propose an automatic high-speed rail CPIII detection system with multi-sensor fusion. The system is based on binocular stereo vision. Dual array camera, Matrox Solios XCL frame grabbers and IPC are used to build the CPIII image acquisition environment. The photoelectric encoder is the trigger of camera. The software HALCON is used to recognize the CPIII image and get the pixel coordinates of CPIII markers' center. Then, we use the intersection measurement principle to calculated the central position of CP III markers in camera coordinate system. The function of CP III image acquisition, automatic identification, calculation are integrated by Visual Studio 2008. Finally, we can realize the non-contact dynamic test of CP III. The CPIII automatic detection system can also be combined with the IMU, GPS, gauge sensors and other detection tools into a small track inspection vehicle and realized the real-time measurement of orbital parameters.
\end{abstract}

Keywords: Automatic identification, calibration, CP III, High-speed rail, halcon, positioning.

\section{INTRODUCTION}

High-speed railway track condition is an important factor related to the safety operation of the train. Therefore the accurate measurement of rail is necessary whether in construction stage or in maintenance stage $[1,2]$. The traditional measurement method is to use the total station, rail gauge and other tools for manual inspection. With the rapid development of sensor technology and computer technology, many developed countries have started using the twodimensional photoelectric sensors (such as CCD, PSD, CMOS sensor).The original detection technology have been replaced by the detection techniques based on laser and camera [3]. The new method has greatly improved the speed, precision, reliability and stability of detection system. So the detection techniques based on laser and camera have become the mainstream of the track detection systems in various countries, such as Japan, the United States, Austria, Germany, Italy, France.

The East-i Comprehensive Test Train [4] made by Japan can detect the track geometry parameters, the catenary, communication signals, the wheel-rail forces, environmental noise and other projects, the maximum test speed is $275 \mathrm{~km} / \mathrm{h}$ [5]. Laserail track measurement system [6,7] made by US ImageMap company use a laser imaging and high-speed image processing technology to replace the photoelectric servo technology [8], the maximum test speed is $300 \mathrm{~km} / \mathrm{h}$. The maximum test speed of EM-250 inspection vehicle made by Plasser Company can reach $250 \mathrm{~km} / \mathrm{h}$, this type of track inspection vehicle adopts the inertial reference measurement technology, photovoltaic conversion technology and multiprocessing technology. It not only can measure the orbital geometry and vehicle vibration parameters, but also can get the parameters of the rail, the wheel-rail forces and record environmental image. The OMWE and RAILAB inspection vehicle made by Germany in the $1980 \mathrm{~s}$ and $1990 \mathrm{~s}$ respectively can detect the rail with the speed of $300 \mathrm{~km} / \mathrm{h}$. The characteristics of its technical is the using of inertial measurement platform [9] constructed by three gyro accelerometers and three servos to detect the orbital geometry parameters. The platform can combined with photoelectric sensors, computer vision [10-15] to get the height, horizontal, alignment of the orbital. Italian Archimedes detection vehicle equipped with lasers, sensors (such as photoelectric sensors, speed sensors, temperature sensors) and IMU. The function mainly includes the detection of track geometry, rail sections, rail wear, current performance between catenary and Pantograph-Catenary, communication signals, body, axle box acceleration, wheel-rail forces. Each subsystem of Archimedes comprehensive test train [11] has a separate database for storing data and the various subsystems can keep pace in speed, time and space.In order to guide the track maintenance scientifically, the test data of all subsystems from the central database were aggregated from the central database and transmitted over a wireless network to the RFI (data processing center) for comprehensive analysis and comparison. The MGV comprehensive inspection vehicle which is made by French can reach the speed of $320 \mathrm{~km} / \mathrm{h}$. The detection projects of the vehicle mainly includes current performance between catenary and Pantograph-Catenary, communication signals, track geometry, rail sections and surfaces, line environment, fasteners, sleepers, ballasts and so on. The GJ-6 orbital inspection vehicle made by China represents the newest technology in domestic track detection. GJ-6 track detection system uses high-speed image processing [12], photoe- 


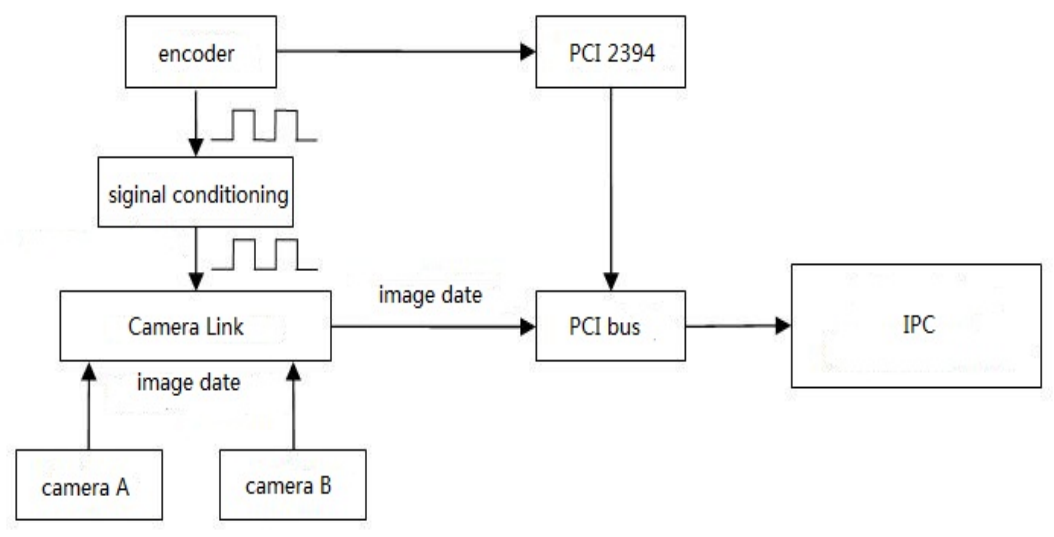

Fig. (1). Hardware structure.

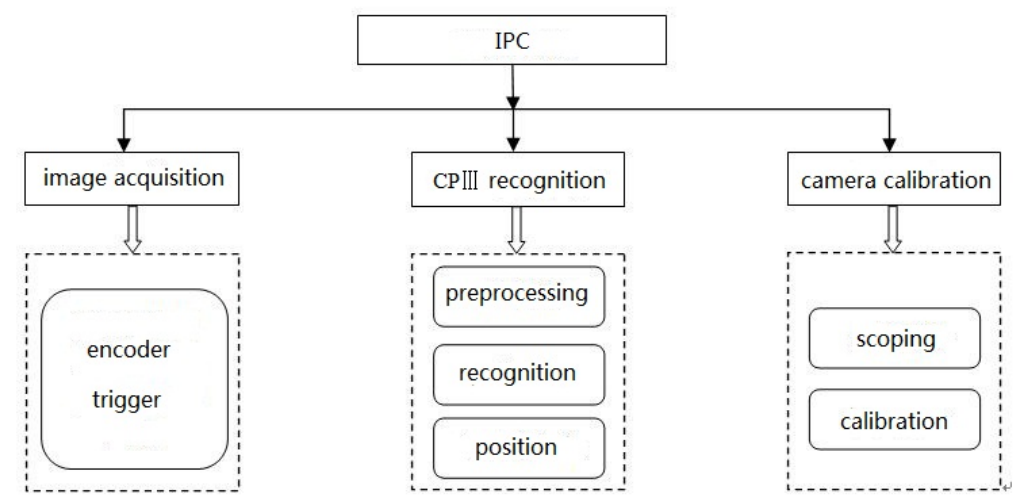

Fig. (2). Software structure.

lectric measurements, the gyro platform, digital filtering, mileage positioning, high-speed computer data processing in real-time and other advanced technology. The characteristics are high-speed, accurate, reliable and stable [13].

At present, the total station, rail gauge and other tools are commonly used in domestic railway track inspection during the construction. The method is easily influenced by the external environment and the detection efficiency is low [14]. In the operation and maintenance stage, track inspection trains are used for the test of rail. Even though the inspection trains have the advantage of high detection speed and high precision, it is dependent on the catenary. What's more, it has complex organizations and high cost. During the CPIII retest stage, it can not be used. To solve these problems, we design a highspeed rail CPIII automatic detection system with multi-sensor fusion. The system is based on binocular stereo vision. It also can be combined with the IMU, GPS, gauge sensors and other detection tools to realize the detection of gauge, alignment, height and horizontal. This will not only meet the demand of the CPIII control network retest and improve the precision, but also have the advantage of simple structure, easy to detect and small Catenary-dependent.

\section{MEASURING PRINCIPLE AND SYSTEM CON- FIGURATION}

This system is based on the principle of binocular stereo vision technology, according to the feature of non-contact measurement technology: high-precision, high efficiency and

low cost, a high-speed rail CPIII automatic detection system of multi-sensor fusion is studied and developed. The system is mainly to establish a CPIII control network testing as the main platform for the detection of high-speed railway routine maintenance, providing a convenient, reliable, and accurate way to measure CP III control network. At the same time, the system which is based on the platform can measure the gauge, rail-to, the level of inequality argument by combining with inertial components, and other measurement tools.

The hardware part of the system is mainly consisted of two linear array camera, IPC, Camera Link frame grabber interface, optical encoder, etc. The Fig. (1) has shown the hardware configuration. Photoelectric encoder generates a pulsed square wave signal with the rotation of the wheels. The signal gets the stable A, B phase pulse after filtering and signal amplification. Then, the pulse is transmitted into the Camera Link frame grabber to control the shoot of camera. When the Camera Link frame grabber receives a rising edge of the square wave pulse, line scan cameras scan one line. In order to achieve an image mileage positioning function, we give the count value of PCI 2394 card to the frame image at the moment.

The software part of system which is based on MFC is developed on Visual Studio 2008 platform to design and develop CPIII automatic detection software. The software mainly includes image acquisition module, CP III recognition 


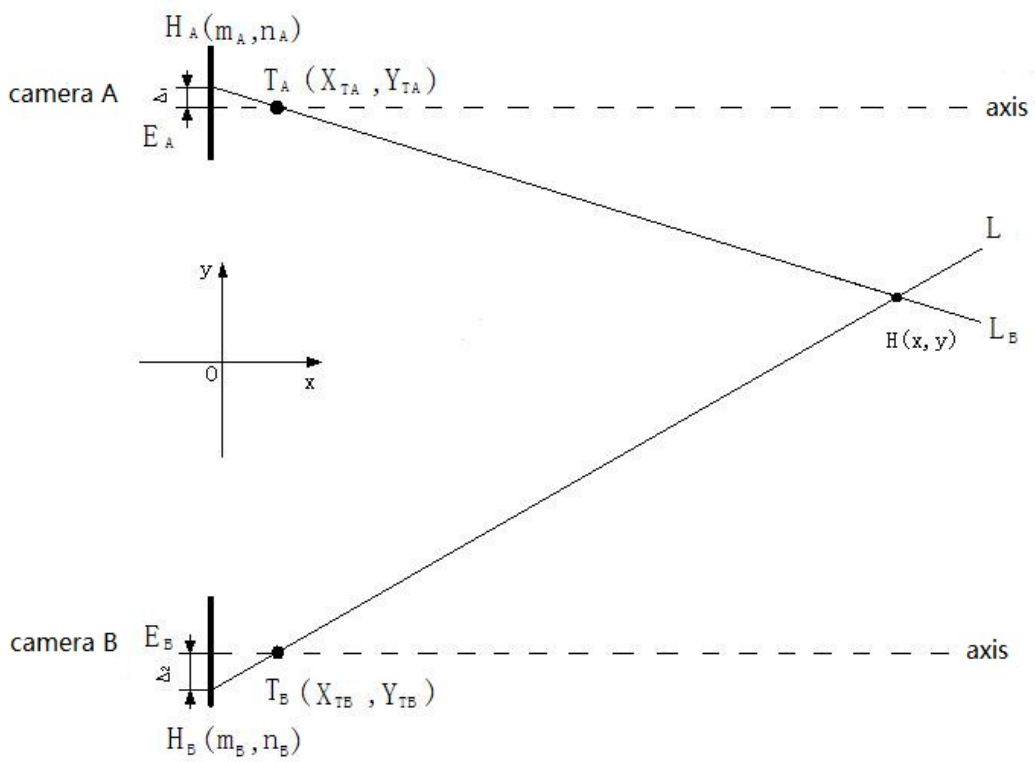

Fig. (3). Binocular stereo vision system.

module and camera calibration module. The Fig. (2) has shown the software structure.

\section{SYSTEM CALIBRATION}

Camera calibration is a very important step in the transition from 2D images transform into 3D computer vision [16]. In this measurement system, calibration is for the purpose of getting the corresponding relationship between input variables and output variables in CPIII automatic measurement system. The Fig. (3) has shown the structure of the binocular stereoscopic measurement system, the origin of the camera coordinate system is $\mathrm{O}$, the input variable is the imaging position of CPIII markers' center $\mathrm{H}(\mathrm{x}, \mathrm{y})$ in linear array camera $\mathrm{A}$ and $\mathrm{B}$ respectively during the calibration, the system constant is the center position of optical, the focal length and inclination, etc, the output variable is CPIII markers' center position coordinate in the camera coordinate system.

The imaging position of CPIII markers' center $\mathrm{H}(\mathrm{x}, \mathrm{y})$ on two linear array CCD is the intersection of LA with linear CCD A H $\mathrm{H}_{\mathrm{A}}\left(\mathrm{m}_{\mathrm{A}}, \mathrm{n}_{\mathrm{A}}\right)$ and $\mathrm{L}_{\mathrm{B}}$ with linear array CCD B H $\mathrm{H}_{\mathrm{B}}\left(\mathrm{m}_{\mathrm{B}}\right.$, $\mathrm{n}_{\mathrm{B}}$ ). The points relative to the image imaging center (optical axis imaging position, linear array image center) $\mathrm{E}_{\mathrm{A}}, \mathrm{E}_{\mathrm{B}}$ 's deviations are $\Delta_{1}$ and $\Delta_{2}$. Owing to the deviation of the center of the imaging position CPIII marker line on the CCD array with respect to the optical axis of the imaging position is proportional to the deviation of the coordinates of the pixel position in the acquisition image with respect to the image center, the center marker located CPIII two line pixels in the camera image coordinates are $\mathrm{a}_{1}, \mathrm{a}_{2}$, the deviations is (2048$\mathrm{a}_{1}$ ), and (2048- $\left.\mathrm{a}_{2}\right)$. Set the slope of linear $\mathrm{L}_{\mathrm{A}}$ and $\mathrm{L}_{\mathrm{B}}$ as $\mathrm{k}_{\mathrm{A}}, \mathrm{k}_{\mathrm{B}}$, using slope-intercept form linear formula:

$y=k_{i} x+b_{i}(i=A, B)$

$\mathrm{k}_{\mathrm{A}}$ and $\mathrm{k}_{\mathrm{B}}$ in the slope-intercept form equation can be calculated from the coordinate values of $H_{A}, T_{A}, H_{B}, T_{B}$ in the camera coordinate system:
$k_{A}=\frac{n_{A}-y_{T A}}{m_{A}-x_{T A}}$

$k_{B}=\frac{n_{B}-y_{T B}}{m_{B}-x_{T B}}$

We can get the value of $b_{A}$ and $b_{B}$ by formula (1):

$b_{A}=y_{T A}-k_{A} x_{T A}$

$b_{B}=y_{T B}-k_{B} x_{T B}$

In practice, the denominator of formula (2), (3) are not zero and $\mathrm{k}_{\mathrm{A}} \neq \mathrm{k}_{\mathrm{B}}$. CPIII marker's center $\mathrm{H}(\mathrm{x}, \mathrm{y})$ is the intersection of $\mathrm{L}_{\mathrm{A}}$ and $\mathrm{L}_{\mathrm{B}}$, so, the position of $\mathrm{H}(\mathrm{x}, \mathrm{y})$ in the camera coordinate system is:

$$
\begin{aligned}
& x=\frac{b_{B}-b_{A}}{k_{A}-k_{B}}=\frac{\left(k_{A} x_{T A}-k_{B} x_{T B}\right)-\left(y_{T A}-y_{T B}\right)}{k_{A}-k_{B}} \\
& y=\frac{k_{A} b_{B}-k_{B} b_{A}}{k_{A}-k_{B}}=\frac{k_{A} k_{B}\left(x_{T A}-x_{T B}\right)-\left(k_{B} x_{T A}-k_{A} x_{T B}\right)}{k_{A}-k_{B}}
\end{aligned}
$$

Put $\mathrm{k}_{\mathrm{A}}, \mathrm{k}_{\mathrm{B}}, \mathrm{b}_{\mathrm{A}}, \mathrm{b}_{\mathrm{B}}$ into formula (4) and (5). We can get the formula (8) and (9).

$$
\begin{gathered}
x=f_{x}\left(m_{A}, n_{A}, m_{B}, n_{B}, x_{Y A}, y_{T A}, x_{T B}, y_{T B}\right) \\
y=f_{y}\left(m_{A}, n_{A}, m_{B}, n_{B}, x_{Y A}, y_{T A}, x_{T B}, y_{T B}\right)
\end{gathered}
$$

In the formula, $x$ and $y$ are the function of $m_{A}, n_{A}, m_{B}$, $\mathrm{n}_{\mathrm{B}}, \mathrm{x}_{\mathrm{TA}}, \mathrm{y}_{\mathrm{TA}}, \mathrm{x}_{\mathrm{TB}}, \mathrm{y}_{\mathrm{TB}}$, focal length, inclination, optical center coordinates are fixed with the process of capuring image every time, only the parameters $\mathrm{mA}, \mathrm{nA}, \mathrm{mB}, \mathrm{nB}$ are changing with the motion of the input variables $H(x, y)$. So the two formulas above can be written as the following form. 


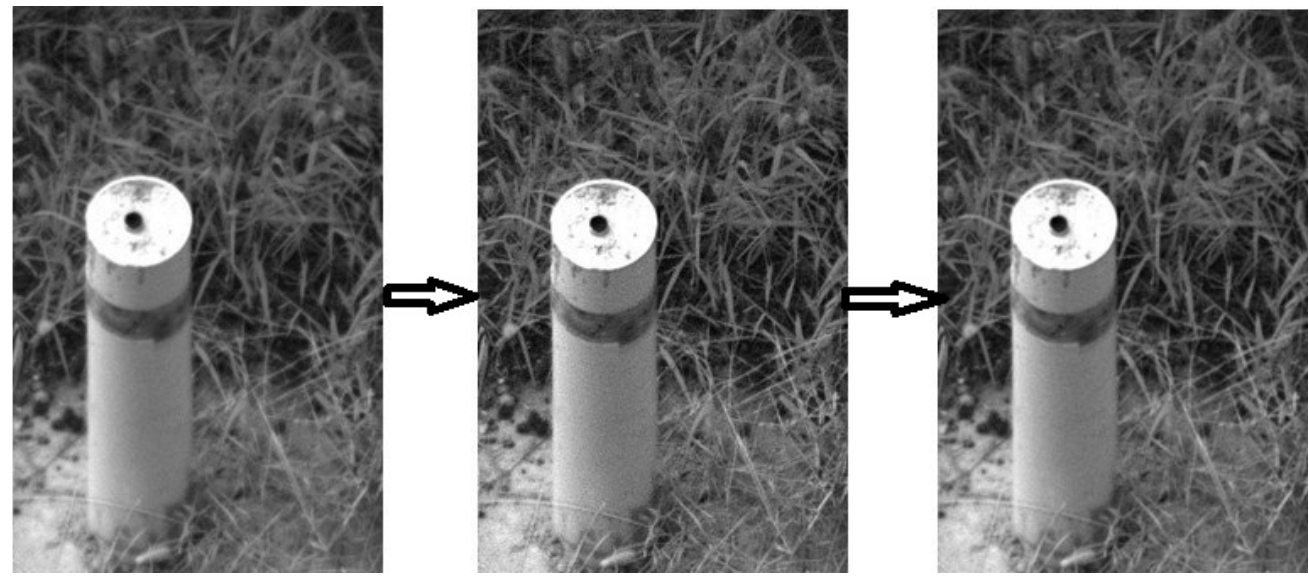

Fig. (4). Image pre-processing.

$x=\frac{c_{0}\left(2048-a_{1}\right)\left(2048-a_{2}\right)+c_{1}\left(2048-a_{1}\right)+c_{2}\left(2048-a_{2}\right)+c_{3}}{c_{4}\left(2048-a_{1}\right)\left(2048-a_{2}\right)+c_{5}\left(2048-a_{1}\right)+c_{6}\left(2048-a_{2}\right)+c_{7}}+c_{8}$

$y=\frac{c_{9}\left(2048-a_{1}\right)\left(2048-a_{2}\right)+c_{10}\left(2048-a_{1}\right)+c_{11}\left(2048-a_{2}\right)+c_{12}}{c_{13}\left(2048-a_{1}\right)\left(2048-a_{2}\right)+c_{14}\left(2048-a_{1}\right)+c_{15}\left(2048-a_{2}\right)+c_{16}}+c_{17}$

In the formula above, $c_{i}(i=0,1, \ldots, 17)$ is the polynomial coefficients based on the variable $\left(2048-\mathrm{a}_{1}\right)$ and $\left(2048-\mathrm{a}_{2}\right)$. Owing to the parameters of the ranging system, such as focal length, inclination, optical center coordinates are constant during image acquisition, so the system is a constant system, the correspondence between the input variables and output variables keep unchanged. We don't need to solve or get each constant parameter during the measurement, we just need to collect the calibration images at different distances and record the location parameters of calibration images in the camera calibration coordinates, using Marquardt method and general anti-global optimization method can calculate the value of the polynomial coefficients in formula (10) (11).

\section{CPIII AUTOMATIC IDENTIFICATION}

CPIII automatic identification include three parts: image preprocessing, image recognition and locating of the markers' central.

The main purpose of preprocessing image is to remove the interference information in the image and reduce the impact of recognition results by the interference information [17]. Firstly, we chose the operator emphasize to enhance image contrast, the calculate formula is (12). In the formula $\mathrm{T}\left(\mathrm{r}_{\mathrm{k}}\right)$ represent the $\mathrm{k}$-th gray level conversion function of original image. $\Sigma n_{j} / N$ represent the sum of gray levels of the pixels from 0 to $\mathrm{j} . \mathrm{N}_{\mathrm{j}}$ represents the the sum of the total number of pixels. $\Sigma \mathrm{P}_{\mathrm{r}}\left(\mathrm{r}_{\mathrm{k}}\right)$ represents the sum of the probability of the gray level occurrence from 0 to $\mathrm{k}$. Then use gauss_image Gaussian blur the image to reduce image noise and reduce the level of detail, highlighting the outline feature, laying the groundwork for subsequent identification, which is calculated as formula (12). Pre-processing the image is shown in Fig. (4).

$$
\begin{aligned}
& S=T\left(\mathrm{r}_{k}\right)=\sum_{j=0}^{k} n_{j} / N=\sum_{j=0}^{k} P_{r}\left(\mathrm{r}_{k}\right) \\
& H(\mathrm{x}, \mathrm{y})=\frac{1}{2 \pi \sigma^{2}} e^{-\frac{x^{2}+y^{2}}{2 \sigma^{2}}}
\end{aligned}
$$

Image recognition, we find the object in the image based on the shape of the template matching. The algorithm can find the position of template in the picture, even if a part of the picture is occluded or interfered. It also is can not be influenced by the change of non-linear illumination [18]. In order to define the similarity of template matching, we define the first template of the target as a set of points $p_{i}=\left(r_{i}\right.$, $\left.c_{i}\right)^{T}$, the direction vector associated with each point is $d_{i}=$ $\left(t_{i}, u_{i}\right)^{T}, i=1, \ldots, n$. Then use the target to create a template and calculate a direction vector $\mathrm{e}_{\mathrm{r}, \mathrm{c}}=\left(\mathrm{v}_{\mathrm{r}, \mathrm{c}}, \mathrm{w}_{\mathrm{r}, \mathrm{c}}\right)^{\mathrm{T}}$ for each point $(r, c)$ in the image. We can get the linear transformation model by $\mathrm{p}_{\mathrm{i}}{ }^{\prime}=\mathrm{A}_{\mathrm{pi}}$ and the corresponding direction vector $\mathrm{d}_{\mathrm{i}}^{\prime}=\left(\mathrm{A}^{-1}\right)^{\mathrm{T}} \mathrm{d}_{\mathrm{i}}$ obtained in the image. Calculate the direction vector and the sum the direction vector's dot product at the corresponding point of picture. Then take it as a post-match score and it is the conversion template similarity measurement at point $\mathrm{q}$, the formula is as follows:

$$
s=\frac{1}{n} \sum_{i=1}^{n} \frac{d_{i}^{\prime}{ }_{i}^{T} e_{q+p^{\prime}}}{\left\|d^{\prime}{ }_{i} \mid\right\| e_{q+p^{\prime}} \|}=\frac{1}{n} \sum_{i=1}^{n} \frac{t_{i}^{\prime} v_{r+r_{i}^{\prime}, c+c_{i}^{\prime}}+u_{i}^{\prime} w_{r+r_{i}^{\prime}, c+c_{i}^{\prime}}}{\sqrt{t_{i}^{\prime 2}+u_{i}^{\prime 2}} \sqrt{v_{r+r_{i}^{\prime}, c+c_{i}^{\prime}}^{2}+w_{r+r_{i}^{\prime}, c+c_{i}^{\prime}}^{2}}}
$$

In order to realize the accuracy of the feature points in the image reach to sub-pixel, find the template points' closest point in the image through algorithm, so that the distances' sum of squares between these points and the corresponding line segment is minimum. The corresponding line segment of image point is defined by the tangent point and the tangent line of points in corresponding template. So the formula of the line, which is through the template points and tangent to the boundary of object is formula (15).

$t_{i}\left(r-r_{i}\right)+u_{i}\left(c-c_{i}\right)=0$

Use $q_{i}=\left(r^{\prime}{ }_{i}, c^{\prime}{ }_{i}\right)$ to represent the points in the image corresponding with the template point $\mathrm{p}_{\mathrm{i}}$. We can get the formula (16). 


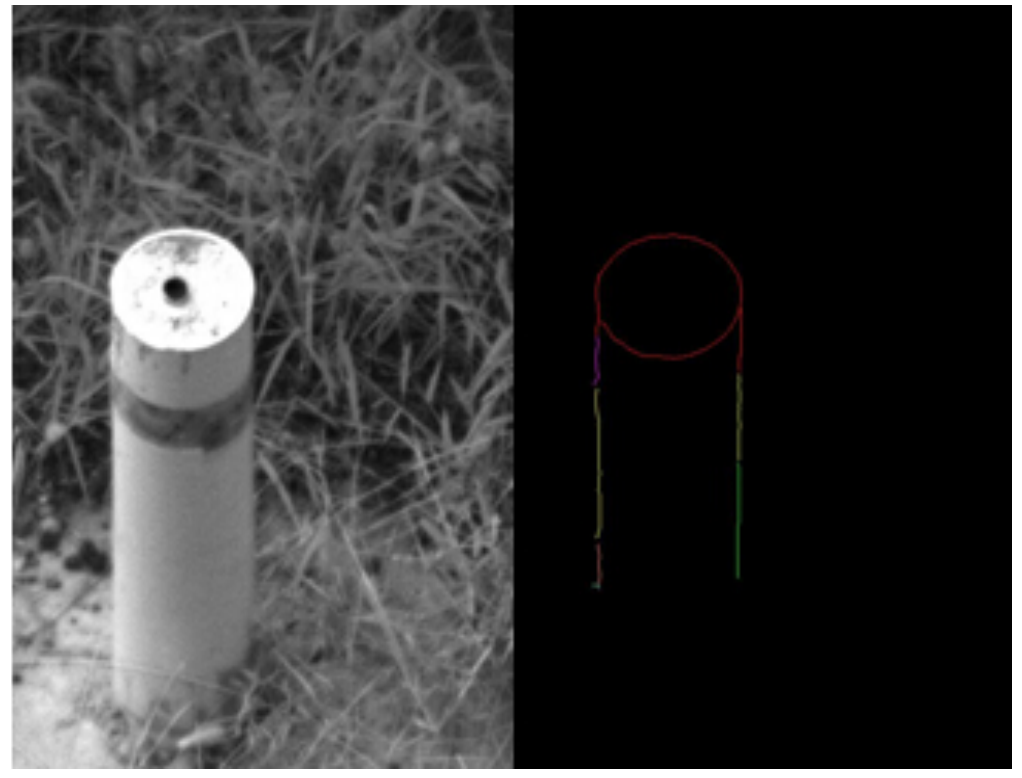

Fig. (5). Image recognition.

$$
d(a)=\sum_{i=1}^{n}\left[t_{i}\left(r_{i}^{\prime}(a)-r_{i}\right)+u_{i}\left(c_{i}^{\prime}(a)-c_{i}\right)\right]^{2} \rightarrow \min
$$

If we obtain more accurate position and orientation parameters, the correspondence may be effected. So we can get higher accuracy by iterative optimization of pose parameters and correspondence. In HALCON, use operater create_shape_model and find_shape_model to generate templates and matching template respectively, the effect shown in Fig. (5).

The location of markers' center, extract the higher brightness oval area in template, use operator threshold to split images and find the light areas of CPIII. If the CPIII is not within the selected range, we can use the operator shape trans to exchange all the border in the previous step and pixels inside the boundary region into new domain. Use operator reduce_domain to remove all parts beyond the threshold. Then extract the lighter areas contains CPIII and use the operator threshold again to obtained black areas of CP III. According to the circular structure, use operator gen_contour_region_xld to create XLD contours and use operator fit_circle_contour_xld to fit the XLD circular outline, set circle formula as formula (17):

$\left(x_{i}-x_{0}\right)^{2}+\left(y_{i}-y_{0}\right)^{2}=R^{2}$

In the formula $\left(\mathrm{x}_{0}, \mathrm{y}_{0}\right)$ is the center, $\mathrm{R}$ is the radius, $\left(\mathrm{x}_{\mathrm{i}}, \mathrm{y}_{\mathrm{i}}\right)$ is the edge point, $\mathrm{i}=1, \ldots, \mathrm{N}, \mathrm{N}$ is the number of edge points. Define the error as formula (18).

$S=\sum_{i=1}^{N}\left[R^{2}-\left(x_{i}-x_{0}\right)^{2}-\left(y_{i}-y_{0}\right)^{2}\right]^{2}$

The coordinates of center $\left(\mathrm{x}_{0}, \mathrm{y}_{0}\right)$ and radius $\mathrm{R}$ can be get by least square method. Finally, use operator gen_circle_contour_xld to get the pixel position $a_{1} 、 a_{2}$, the two positions are CPIII marker's center in the images get by camera A and B. The positioning process of marker's center has shown in Fig. (6).

Part of the code is as follows:

threshold (ImageGauss, Regions, 235, 255)

shape_trans (Regions, RegionTrans, 'convex')

reduce_domain (ImageGauss, RegionTrans, ImageReduced)

threshold (ImageReduced, Region, 0, 90)

gen_contour_region_xld (Region, Contours, 'border')

fit_circle_contour_xld (Contours, 'algebraic', -1, 0, 0, 3, 2, Row, Column, Radius, StartPhi, EndPhi, PointOrder)

gen_circle_contour_xld (ContCircle, Row, Column, Radius, $0,6.283 \overline{18}$, 'positive', 1 )

\section{THE CACULATION OF CPIII MARKER'S CEN- TER}

According to the calibration principle above, we collect the calibration images in different distances and record the location parameters of calibration images in camera coordinate system. Then, use the Marquardt method and general anti-global optimization method to calculate the values of the polynomial coefficients, as shown in Table $\mathbf{1}$.

$a_{1}, a_{2}$ are the pixel coordinate of CP III markers' center in the image of camera A and camera $B$. Then insert $a_{1} 、 a_{2}$ in formula (8) and (9), we can get the point coordinates in the camera coordinate system. In the experiment, we measure the changing target point several times, the result of calculated and the measured values are shown in Table 2 . We can see from the result that the accuracy of the calculated values are within $1 \mathrm{~mm}$. 

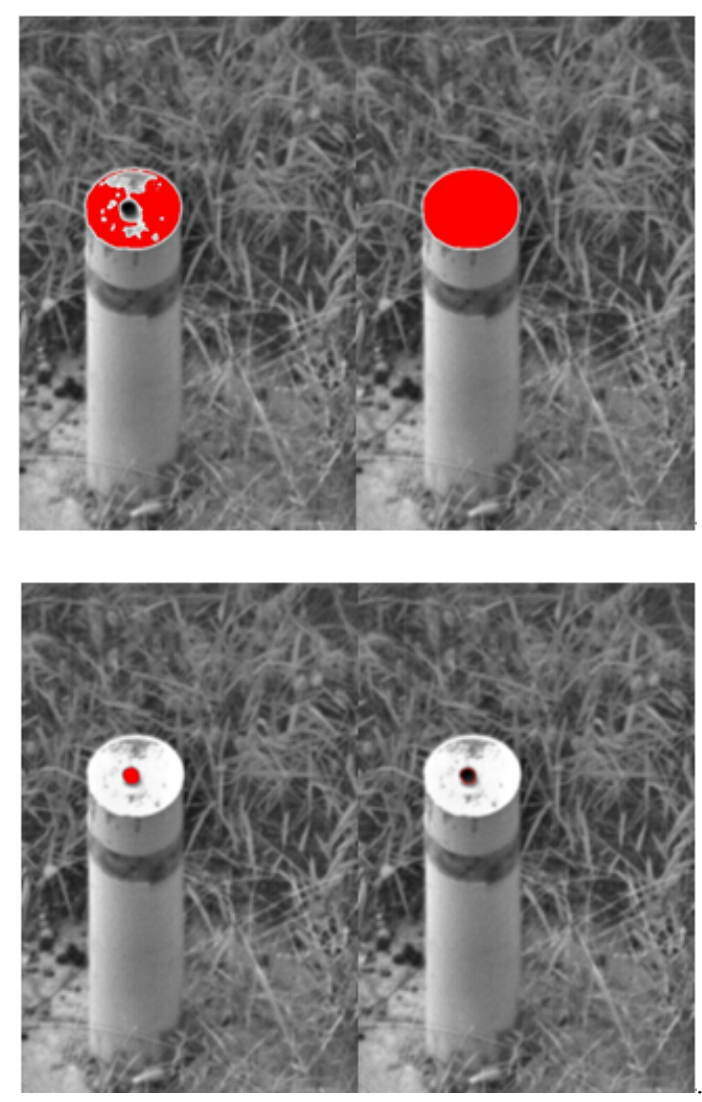

Fig. (6). The Positioning Process of Marker's Center.

Table 1. The Parameters of Calibration.

\begin{tabular}{|c|c|c|c|}
\hline Parameter & Value & Parameter & Value \\
\hline \hline $\mathrm{C}_{0}$ & 0.117829050067943 & $\mathrm{C}_{9}$ & 0.217294442688392 \\
\hline $\mathrm{C}_{1}$ & 21655.6962839942 & $\mathrm{C}_{10}$ & 4524.74939092065 \\
\hline $\mathrm{C}_{2}$ & -21705.2790630025 & $\mathrm{C}_{11}$ & 30962.047464585 \\
\hline $\mathrm{C}_{3}$ & -354.547573901947 & $\mathrm{C}_{12}$ & $2.59928980730993 \mathrm{E}-5$ \\
\hline $\mathrm{C}_{4}$ & $2.0846111223893 \mathrm{E}-6$ & $\mathrm{C}_{13}$ & 36.947336068678 \\
\hline $\mathrm{C}_{5}$ & 0.396953567416608 & $\mathrm{C}_{14}$ & -37.46945533327879 \\
\hline $\mathrm{C}_{6}$ & 0.397929886963554 & $\mathrm{C}_{15}$ & 3879.43487435403 \\
\hline $\mathrm{C}_{7}$ & 36.981335182326 & $\mathrm{C}_{16}$ & 771.226990483799 \\
\hline $\mathrm{C}_{8}$ & -54468.954284934 & $\mathrm{C}_{17}$ & \\
\hline
\end{tabular}

Table 2. The Result of Calculated and the Measured Values.

\begin{tabular}{|c|c|c|c|c|c|c|c|}
\hline $\mathbf{a}_{\mathbf{1}}$ & $\mathbf{a}_{\mathbf{2}}$ & $\begin{array}{c}\text { Calculated } \\
\text { value } \mathbf{x} \\
\mathbf{( m m )}\end{array}$ & $\begin{array}{c}\text { Calculated } \\
\text { value } \mathbf{y} \\
\mathbf{( m m}\end{array}$ & $\begin{array}{c}\text { Measured } \\
\text { Value } \mathbf{x}_{\mathbf{0}} \\
(\mathbf{m m})\end{array}$ & $\begin{array}{c}\text { Measured } \\
\text { Value } \mathbf{y}_{\mathbf{0}} \\
(\mathbf{m m})\end{array}$ & $\begin{array}{c}\mathbf{y}_{\mathbf{0}}-\mathbf{x} \\
(\mathbf{m m})\end{array}$ \\
\hline \hline 3072 & 31 & 1800.056111 & 247.1967494 & 1800 & 248 & -0.056111 & 0.8032506 \\
\hline 3228 & 187 & 1800.712254 & 297.6561236 & 1800 & 298 & -0.712254 & 0.3438764 \\
\hline
\end{tabular}


Table 2. contd...

\begin{tabular}{|c|c|c|c|c|c|c|c|}
\hline $\mathbf{a}_{1}$ & $\mathbf{a}_{2}$ & $\begin{array}{c}\text { Calculated } \\
\text { value } x \\
(\mathbf{m m})\end{array}$ & $\begin{array}{c}\text { Calculated } \\
\text { value y } \\
(\mathrm{mm})\end{array}$ & $\begin{array}{c}\text { Measured } \\
\text { Value } x_{0} \\
(\mathbf{m m})\end{array}$ & $\begin{array}{c}\text { Measured } \\
\text { Value } y_{0} \\
(\mathrm{~mm})\end{array}$ & $\begin{array}{c}\mathbf{X}_{0}-\mathbf{X} \\
(\mathbf{m m})\end{array}$ & $\begin{array}{c}\mathbf{y}_{0}-\mathbf{y} \\
(\mathrm{mm})\end{array}$ \\
\hline 3383 & 340 & 1800.209807 & 347.5076708 & 1800 & 348 & -0.209807 & 0.4923292 \\
\hline 3539 & 495 & 1800.321605 & 397.7517483 & 1800 & 398 & -0.321605 & 0.2482517 \\
\hline 3168 & 288 & 1900.598783 & 297.3426287 & 1900 & 298 & -0.598783 & 0.6573713 \\
\hline 3316 & 433 & 1899.335846 & 347.5362720 & 1900 & 348 & 0.664154 & 0.4637280 \\
\hline 3610 & 726 & 1900.124767 & 447.7802425 & 1900 & 448 & -0.124767 & 0.2197575 \\
\hline 3257 & 519 & 1999.494894 & 348.2072981 & 2000 & 348 & 0.505106 & -0.2072981 \\
\hline 2673 & 69 & 2099.257015 & 147.8857481 & 2100 & 148 & 0.742985 & 0.1142519 \\
\hline 2804 & 200 & 2100.014983 & 197.6214694 & 2100 & 198 & -0.014983 & 0.3785306 \\
\hline 2936 & 332 & 2100.776072 & 247.7393153 & 2100 & 248 & -0.776071 & 0.2606847 \\
\hline 3070 & 463 & 2099.119048 & 298.1978073 & 2100 & 298 & 0.880952 & -0.1978073 \\
\hline 2522 & 39 & 2200.997408 & 97.8627440 & 2200 & 98 & -0.997408 & 0.1372560 \\
\hline 2745 & 366 & 2299.466276 & 197.7283721 & 2300 & 198 & 0.533724 & 0.2716279 \\
\hline 2866 & 486 & 2299.329586 & 248.0542093 & 2300 & 248 & 0.670414 & -0.0542093 \\
\hline 2376 & 98 & 2399.615076 & 48.4426985 & 2400 & 48 & 0.384924 & -0.4426985 \\
\hline 2491 & 213 & 2400.546326 & 98.5757570 & 2400 & 98 & -0.546326 & -0.5757570 \\
\hline 2605 & 326 & 2400.382520 & 148.1944203 & 2400 & 148 & -0.382520 & -0.1944203 \\
\hline 2719 & 439 & 2400.197291 & 197.7804528 & 2400 & 198 & -0.197291 & 0.2195472 \\
\hline 2366 & 178 & 2499.485931 & 48.3035745 & 2500 & 48 & 0.514069 & -0.3035745 \\
\hline 2476 & 288 & 2500.461314 & 98.3097423 & 2500 & 98 & -0.461314 & -0.3097423 \\
\hline 2587 & 397 & 2499.101042 & 148.5938924 & 2500 & 148 & 0.898958 & -0.5938924 \\
\hline 2916 & 724 & 2499.459632 & 297.8161290 & 2500 & 298 & 0.540368 & 0.1838710 \\
\hline 2357 & 252 & 2599.503890 & 48.2730962 & 2600 & 48 & 0.496110 & -0.2730962 \\
\hline 2462 & 356 & 2599.260544 & 97.8940619 & 2600 & 98 & 0.739456 & 0.1059381 \\
\hline 2568 & 462 & 2600.251157 & 148.0578437 & 2600 & 148 & -0.251157 & -0.0578437 \\
\hline
\end{tabular}




\section{CONCLUSION}

In this paper, we design a high-speed rail CPIII automatic detection system with multi-sensor fusion based on binocular stereo measurement technology. The system can realize automatic measurement of CPIII which is along the high-speed rail, it also can greatly shorten the cycle of CPIII control network measurement and reduce the burden of manual measurements. Through the experiments, we verify the feasibility and accuracy of the system. Tests show that the system can make good use in orbit testing field, the measurement accuracy can reach $1 \mathrm{~mm}$. The CPIII automatic detection system can also be combined with the IMU, GPS and gauge sensors and other detection tools into a small track inspection car and real time measure the orbital parameters. This will meet the CPIII control network retest demand and improve the CPIII control network retest precision. It has a simple structure and easy to detect the rail without the catenary. These are the advantages when compared with highspeed train

\section{CONFLICT OF INTEREST}

The authors confirm that this article content has no conflicts of interest.

\section{ACKNOWLEDGEMENTS}

This work is supported by Natural Science Foundation Research Project of Shaanxi, China (NO.20110476), the Basic Research program of Central Universities, China (NO.chd2011TD006), the Basic Research program of Central Universities, China (NO.chd2010JC021).

\section{REFERENCES}

[1] W. Al-Nuaimy, A. Eriksen, and J. Gasgoyne, "Train-Mounted GPR for High-speed Rail Trackbed Inspection", In: $10^{\text {th }}$ International Conference on Ground Penetrating Radal, Deljt, Netherlands, 2004, pp. $21-24$.

[2] S. Ono, A. Numakura, and T. Odaka, "High-speed Track Inspection Technologies", JR EAST Technical Review, pp. 9-13, 2003

[3] J. Santos, M. Hempel, and H. Sharif, "Sensing Techniques and Detection Methods for Train Approach Detection", In: Proceedings of Vehicular Technology Conference (VTC Fall), IEEE $78^{\text {th }}$ Las Vegas, 2013, pp. 1-5.

[4] H. Tsunashima, Y. Naganuma, A. Matsumoto, T. Mizuma, and H. Mori, "Japanese railway condition monitoring of tracks using in- service vehicle", In: $5^{\text {th }}$ IET Conference on Railway Condition Monitoring and Non-Destructive Testing, 2011, p. 6.

[5] H. Tsunashima, Y. Naganuma, A. Matsumoto, T. Mizuma, and H. Mori, "Japanese railway condition monitoring of tracks using inservice vehicle", In: $5^{\text {th }}$ IET Conference on Railway Condition Monitoring and Non-Destructive Testing (RCM 2011), 2011, pp. 16.

[6] ImageMap Inc. http://www.imagemap.com/laserrail.htm (laserail unattended geometry measurement system (UGMS) for service trains), 2006

[7] P.F. Weston, C.S. Ling, C.J. Goodman, C. Roberts, P. Li, and R.M Goodall, "Monitoring lateral track irregularity from in-service railway vehicles", Rail and Rapid Transit, vol. 221, pp. 89-100 Jan 2007.

[8] Q. Wang, S. Kang, L. Zuo, and Y. Zhou, "A novel elctro-optical servo control technology and its application", In: Fourth International Conference on Genetic and Evolutionary Computing (ICGEC), 2010, pp. 791-794.

[9] B. Feng, X. Zhang, and H. Zhao, "The research of motion capture technology based on inertial measurement dependable", In: IEEE $11^{\text {th }}$ International Conference on Autonomic and Secure Computing, 2013, pp. 238-243.

[10] S. Zheng, X. Chai, X. An, and L. Li, "Railway track gauge inspection method based on computer vision", In: IEEE International Conference on Mechatronics and Automation, 2012, pp. 12921296.

[11] M. Moretti, M. Triglia, and G. Maffei, "ARCHIMEDE The First European Diagnostic Train for Global Monitoring of Railway Infrastructure", In: 2004 IEEE Intelligent Vehicles Symposium, Parma, Italy, 2004, pp. 14-17.

[12] X. Zhang, Y. Li, J. Wang, and Y. Chen, "Design of high-speed image processing system based on FPGA", In $9^{\text {th }}$ International Conference on Electronic Mesurement and Instruments, ICEMI '09., 2010, pp. 65-69.

[13] Y. Li, W. Wang, and S. Wei, "Data transmission system design of digital sensor in track inspection system based on CAN bus," China Railway Science, vol. 33, pp. 122-126, Aug. 2012.

[14] R. Huber-Mork, M. Nolle, A. Oberhauser, and E. Fischmeister, "Statistical Rail Surface Classification Based on 2D and 21/2D Image Analysis", Advanced Concepts For Intelligent Vision Systems Lecture note in computer, vol. 6474, pp. 50-61, Dec. 2010.

[15] Y. Yakimovsky, and R. Cunningham, "A system for extracting three dimensional measurement from a stereo pair of cameras". Computer Graphics and Image Processing, vol. 8, no. 7, pp. 195210, 1978.

[16] Z.Y. Zhang, "A flexible new technique for camera calibration", IEEE Transactions on Pattern Analysis and Machine Intelligence, vol. 11, no. 22, pp. 1330-1334, 2000.

[17] S. Kim, and S. Chol, "The Coil recognition system for an unmanned crame using stereo vision", In: The $30^{\text {th }}$ Annual Conference of the IEEE industrial Electronic Society, November, Busan, Korea, pp. 1235-1239, 2004.

[18] M. Sonka, V. Hlavac, and R. Boyle. "Image Processing", Analysis and Machine Vision ( $2^{\text {nd }}$ Edition), New York: Thomson Press, 2002, pp. 460-469.

Received: September 22, 2014

(C) Han et al.; Licensee Bentham Open.

This is an open access article licensed under the terms of the Creative Commons Attribution Non-Commercial License (http://creativecommons.org/licenses/by-nc/3.0/) which permits unrestricted, non-commercial use, distribution and reproduction in any medium, provided the work is properly cited. 